\title{
Relationship between EFL Learners' Self-efficacy and Imposter Phenomenon and Their Effects on Learners' Writing Ability
}

\author{
Morteza Yamini and Forough Behbahani Mandanizadeh \\ (Islamic Azad University, Shiraz Branch, Iran) \\ doi:10.7575/aiac.alls.v.2n.1p.70
}

\begin{abstract}
This study investigated the relationship between self-efficacy and imposter phenomenon and their effects on EFL learners' writing ability. Participants were 94 male and female university students. The aim was to find out how self-efficacy and imposter phenomenon would be related, how these personal factors would relate to writing ability, and whether gender and proficiency level would moderate between the personal factors and writing.
\end{abstract}

The instruments were Writing Self-Efficacy Scale, Harvey Imposter Phenomenon Questionnaire, Oxford Quick Placement Test, and a written essay on a specified topic. The findings revealed self-efficacy and impostorism were positively related, but only writing selfefficacy could predict students' writing ability. While proficiency level affected writing ability, gender differences had no effects.

\section{Introduction}

Language is one of the most important tools of the technical man. Through listening and reading one gets valuable insights into other people's experiences, and, equally important, through speaking and writing one shares with others one's own experiences and ideas. The ability to write effectively is increasingly gaining significance in our global community and instruction in writing is thus assuming growing importance in both second and foreign language education. The ability to write in a second language is widely recognized as an important skill for educational, business and personal reasons. Hayes and Flower (1980, cited in Weigle, 2002) described the writing process in terms of the task environment, the writer's long term memory, and cognitive processes. In the area of writing, researchers have confirmed that students' confidence in their writing skills is related both to writing competence and to academic motivation variables such as writing self-concept, writing apprehension, achievement goals, and the perceived value of writing (Pajares, Hartley, \& 
Valiante, 2000). Since the present study aims at studying writing ability in relation to selfefficacy and imposter phenomenon, a brief introduction of the traits are in order.

\section{Self-efficacy}

According to Bandura (1986), human achievement depends on interactions between one's behaviors, personal factors (e.g., thought, belief), and environmental conditions. Each variable interacts with the other two to produce learning results that are idiosyncratic to the individual. Bandura (1978, cited in Pajares, 1996) called this interaction reciprocal determinism. Learners obtain information to appraise their self-efficacy from their actual performances, their vicarious experiences, the persuasions they receive from others, and their physiological reactions. Self-efficacy beliefs influence task choice, effort, persistence, resilience, and achievement. Pajares and Schunk (2002) mention that self-efficacy beliefs influence students' behavior in a number of ways. First, they influence the choices that students make; students engage in tasks about which they feel confident and avoid those in which they do not. At lower levels of schooling, this can be an exercise, for students often have very little choice over the activities in which they must engage. As they get older, however, they have greater control over course and activity selection, and their confidence influences these decisions.

Self-efficacy beliefs also help determine how much effort students will expend on an activity and how long they will persevere-the higher the sense of efficacy, the greater the effort expenditure and persistence. Self-efficacy beliefs also affect behavior by influencing students' emotional reactions. The influence of self-efficacy beliefs, as mentioned above, can also be attributed to foreign learners' behavior toward learning a new language. In addition, writing as one of the skills to be learned by foreign learners is not an exception.

\section{Imposter phenomenon}

The term 'Impostor Phenomenon' (IP) was coined by Pauline Rose Clance, a psychology professor, and Suzanne Imes, a psychotherapist, in 1978 to describe a sample of more than 150 high-achieving women (Wick, 1997). Impostor Phenomenon (also known as the Impostor Syndrome) has been defined in different ways of which the following are but examples: the persistent belief in one's lack of competence, skill or intelligence in the face of consistent

objective data to the contrary; an internal experience of intellectual fraudulence, particularly among high-achievers; the belief that one does not deserve one's career success and that 
others have been deceived into thinking otherwise; an intense subjective fear of the inability to repeat past success; a self-concept that one's record of accomplishments is not due to ability but rather only due to luck, fate, charm, attractiveness, or having manipulated other people's impressions; the secret conviction that one is truly less intelligent and competent than one appears; and an unrealistic sense of one's competence in which one downplays strengths and exaggerates or does not tolerate any deficiencies or weaknesses.

Want \& Kleitman (2006) refer to the sound links between impostor tendencies and personality. According to them, impostor feelings have been shown to correlate with neuroticism, conscientiousness and extraversion personality dimensions. Thus, imposter phenomenon provides a useful framework for learners' writing ability. As such, the purpose of this study was to shed some light on the relationship between two internal constructs of self-efficacy and imposter phenomenon and learners' writing ability and to investigate if the said constructs could predict learners' performance on a writing task.

\section{Overview}

Although no previous studies dealing with the relationship between imposter phenomenon and self-efficacy, and their predictive power in relation to foreign language learners' writing ability were found, a wealth of research findings indicate that self-efficacy correlates with achievement outcomes. Findings of two studies (Pintrich \& Garcia, 1991 cited in Ghoreishi, 2003; Multon, Brown, \& Lent, 1991) have shown that students who believe themselves to be capable of successfully completing an academic task persist much longer than those who do not believe so. Students needed to have both the will and the skill to be successful in classrooms.

Thompson, Davis and Davidson (1998), in a study involving 164 undergraduate psychology students (126 females, 38 males), investigated (1) the affective and attributional reactions of imposters following success and failure feedback and (2) associations between imposter fears and cognitive dispositions which are known to have links with either perfectionism or depression. The results supported the elements of perfectionism in the extent to which imposters externalized success, set high standards for self-evaluation and were self-critical. Another finding was that impostors' greater reporting of negative emotions (anxiety, dissatisfaction, guilt, humiliation), together with their tendency to attribute failure internally and overgeneralize a single failure to their overall self-concepts corroborated the links 
between imposter fears, anxiety, and depression. Therefore, an imposter fear is an anxietyrelated experience and is consistent with low self-esteem. Individuals with low self-esteem tend to make overgeneralizations and this is reported to be a powerful predictor of depression in both male and female college students.

Pajares, Johnson and Miller (1999) investigated the nature of gender differences in writing self-beliefs held by elementary school students in Grades 3, 4 and 5 ( $N=363)$. Girls were judged superior writers, but there were no gender differences in writing self-efficacy after controlling for writing aptitude. However, most girls believed that they were better writers than other girls or boys in their class or in their school. Only writing self-efficacy beliefs and aptitude did predict writing performance in a path analysis that included writing apprehension, self-efficacy for self-regulation, and perceived usefulness of writing. The reported data were consistent with Bandura's (1986) social cognitive theory and suggested that boys and girls use a different metric when responding to the traditional self-efficacy scale.

A study by Pajares and Valiante (2001) is grounded on the contention that some gender differences in social, personality, and academic variables may be a function of gender orientation-the stereotypic beliefs about gender that students hold-rather than of gender itself. Participants were 497 students in a public middle school (250 girls and 247 boys). Writing self-efficacy, writing apprehension, and writing self-concept were among the instruments used in this study. The findings revealed that many gender differences in writing motivation and achievement of middle school students might be a function of gender orientation. Regardless of the strength of their feminine orientation beliefs, boys reported a stronger preference than did girls for wanting to succeed in writing so as to display their competence. All gender differences favoring girls in writing motivation and achievement were rendered nonsignificant when feminine orientation beliefs were controlled.

Finally, Caselman, Self, and Self (2006) conducted a research to study the predictors of imposter phenomenon among a sample of 11th and 12th graders. Multiple regression analyses indicated that significant predictors of IP scores for females were Friend Support, Classmate Support and Dependability. Only Friend Support significantly predicted IP scores for males. The unique variance explained (UVE) by each of the variables was fairly modest, suggesting 
that the variables were explaining a considerable amount of the same portion of the variance, particularly for females.

\section{Study}

\section{Participants}

Ninety-four undergraduate students (68 female, 26 male) majoring in English at Shiraz Azad University participated in this study. The participants were given a placement test (Allan, 2004) and on the basis of the results, they were classified into high, intermediate and low levels. In this way, there were 27 low, 42 intermediate, and 25 high level students.

\section{Instruments}

The instruments used in this study consisted of two tests, namely, Oxford Quick Placement Test, an essay-writing test, and two questionnaires, namely, Imposter Phenomenon Scale (Harvey, 1982, as cited in Fried-Buchalter, 1992) and Writing Self-Efficacy Scale (Pajares, \& Valiante, 1999). In order to make the imposter questionnaires clear for all participants, the items were translated into their native language (Persian). This was then back translated into English and was compared to the original version. The comparison showed that the two versions included the same concepts and tapped the same issues.

\section{Procedures}

This study was conducted in two sessions. During the first session, the participants were informed of the objectives and significance of the research, they were Oxford Quick Placement Test. During the second session, participants were initially asked to provide some demographic information about themselves. All respondents were ensured that the basic principles of confidentiality would be observed and they would remain anonymous. Following this, in order to avoid the order effect, the participants were randomly divided into two groups. The first group was asked to complete 9 items on Writing Self-efficacy Questionnaire and 12 items on Imposter Phenomenon Questionnaire. They had 30 minutes to complete the questionnaires. At the same time the second group wrote an essay on "My Idea of a Perfect Day". When the time was over, those who had the questionnaires were asked to write the essay and the students in the second group responded to the questionnaires. 


\section{Analysis}

First, to determine the relationship between learners' self-efficacy and imposter phenomenon, a correlation analysis was used. Moreover, a regression analysis was conducted to make a prediction about learners' performance on the writing task from their self-efficacy or imposter phenomenon. Finally, two-way ANOVAs were run to determine whether sex and proficiency level as moderator variables affect the learners' self-efficacy/ imposter phenomenon/ writing ability.

\section{Results and discussion}

Correlational analysis

Correlational analyses for Self-efficacy, Imposter Phenomenon and Writing Performance were run. The results are summed up in Table 1.

Table 1: Correlations among self-efficacy, imposter phenomenon and writing

\begin{tabular}{llll}
\hline & & IP & Writing \\
\hline SE & Pearson Correlation & $.316^{* *}$ & $.312^{* *}$ \\
& Sig. (2-tailed) & .002 & .002 \\
& N & 94 & 94 \\
IP & Pearson Correlation & & .134 \\
& Sig. (2-tailed) & ------ & .197 \\
& N & & 94 \\
\hline
\end{tabular}

As the above table illustrates, the correlational analyses reveal a positive relationship between self-efficacy and imposter phenomenon. The results were not in line with Chrisman's (1995, cited in Thompson, Davis \& Davidson, 1998). So, this study did not support the negative correlation between self-efficacy and imposter feelings since there was a small but positive correlation between SE and IP $(r=.316)$. This implies that higher imposter feelings are slightly associated with higher self-efficacy in writing. A possible reason can be due to the weak predictive value of general rather than specific measures of imposter phenomenon. There is also a positive relationship between self-efficacy and writing $(r=.312)$ at the .01 level of significance. It indicates that an increase in SE is associated with an increase in students' writing ability. The current study confirmed Pajares and Johnson's (1993) as well as Pajares, Johnson, and Miller's (1999) findings. This can also be in line with Klassen's (2007) findings that revealed the writing efficacy beliefs of early adolescents with and without learning disabilities. However, the relationship between writing and imposter phenomenon is 
not statistically significant. It seems that imposter fears do not reflect themselves in learners' writing ability.

\section{Analysis of variance}

To determine the effect of proficiency level and sex as two independent variables on selfefficacy, imposter phenomenon, and writing as dependent variables, three sets of two-way ANOVA were run. The obtained F-value for sex revealed a significant effect on writing selfefficacy (Table 2). The mean for male students was found to be 76.19 while for female students it was 65.09. This shows that male students reported higher writing self-efficacy than females did.

Table 2: Results of two-way ANOVA (writing self-efficacy)

\begin{tabular}{llllll}
\hline Source & Sum of Squares & df & Mean Square & F & Sig. \\
\hline Sex & 1676.618 & 1 & 1676.618 & 6.86 & $.010^{*}$ \\
Level & 1245.532 & 2 & 622.766 & 2.54 & .084 \\
Sex * Level & 268.161 & 2 & 134.080 & .549 & .580 \\
Total & 26225.376 & 93 & & & \\
\hline
\end{tabular}

Table 3: Post hoc analysis on the effect of level on writing self-efficacy

\begin{tabular}{lllll}
\hline (I) level & (J) level & Mean Difference (I-J) & Std. Error & Sig. \\
\hline 1(high) & $\mathbf{2 ( m i d )}$ & 7.3140 & 3.94912 & .186 \\
& 3(low) & $12.0333^{*}$ & 4.33918 & .025 \\
2 (mid) & 3(low) & 4.7193 & 3.85634 & .476 \\
\hline
\end{tabular}

The findings are in line with those reported by Pajares, Johnson and Miller (1999), Pajares and Graham, (1999); Pajares and Miller, (1995); and Pintrich and Schunk, (1996) that revealed a significant difference between the performances of girls and boys on the selfefficacy scale. Also the mean for low level learners significantly differs from that of high level learners at the .05 level. So there is a difference between low and high level learners in terms of their writing self-efficacy. From low to intermediate or from intermediate to low, no difference is seen, but high level learners are more self-efficacious than low level ones. This finding can be compared to that of Collins (1982 cited in Pajares \& Miller, 1995) who mentioned that ability was related to performance and children with high self-efficacy did better in completing more problems correctly. 
Regarding imposter phenomenon, there was no significant effect of sex or proficiency level on learners' imposter phenomenon scores nor was there an interaction between the said variables (Table 4).

Table 4: Results of two-way ANOVA (imposter phenomenon)

\begin{tabular}{llllll}
\hline Source & Sum of Squares & df & Mean Square & F & Sig. \\
\hline Sex & 3.082 & 1 & 3.082 & .117 & .734 \\
Level & 19.480 & 2 & 9.740 & .369 & .693 \\
Sex * Level & 1.119 & 2 & .560 & .021 & .979 \\
\hline Total & 2355.713 & 93 & & &
\end{tabular}

The finding that sex had no significant effect on imposter phenomenon is consistent with the findings of Caselman, Self and Self (2006), and Thompson, Davis and Davidson (1998) who found that both males and females experienced the secret feelings of IP almost with the same degree. No significant effect of proficiency level on imposter phenomenon reveals that being imposter does not depend on the proficiency level of the students. It can be the characteristics of any person at different levels of proficiency.

Finally, the two-way ANOVA dealing with the effect of proficiency level and sex on writing ability (Table 5) yielded a non-significant main effect for $\operatorname{sex}(\mathrm{F}=2.64$, $\mathrm{df}=1$, sig. $=.108)$. This can be compared to the study by Pajares and Valiante, (2001) who reported that all gender differences favoring girls in writing motivation and achievement were rendered nonsignificant and they attributed gender differences in writing motivation and achievement of middle school students to a function of gender orientation rather than of gender.

Table 5: Results of two-way ANOVA (writing ability)

\begin{tabular}{llllll}
\hline Source & Sum of Squares & df & Mean Square & F & Sig. \\
\hline Sex & 107.427 & 1 & 107.427 & 2.641 & .108 \\
Level & 1550.033 & 2 & 775.017 & 19.055 & $\mathbf{. 0 0 0 *}$ \\
Sex * Level & 72.801 & 2 & 36.401 & .895 & .412 \\
\hline Total & 6484.915 & 93 & & &
\end{tabular}

Table 6: Post hoc analysis on the effect of level on writing ability

\begin{tabular}{lllll}
\hline (I) level & (J) level & Mean Difference (I-J) & Std. Error & Sig. \\
\hline 1(high) & 2(mid) & $10.8305^{*}$ & 1.61099 & .000 \\
& 3(low) & $13.7511^{*}$ & 1.77011 & .000 \\
\hline 2(mid) & 3(low) & 2.9206 & 1.57314 & .184
\end{tabular}


The result pertaining to the main effect of proficiency level on writing ability was significant $(\mathrm{F}=19.05, \mathrm{df}=2, \mathrm{sig}=.000)$. The mean score for high level learners significantly differed from that of the intermediate students $(\mathrm{MD}=10.83$, $\mathrm{sig}=.000)$ and low level learners $(\mathrm{MD}=13.75, \mathrm{sig}=.000)$ at the .05 level. So there was a difference between low, mid and high level learners in terms of their writing performance, but there was not any difference between the intermediate and low level learners in this regard. It shows that the writing ability of the learners increases as their proficiency level goes up, but this increase is gradual. The results are in line with the study conducted by Goh and Foong (1997) which showed that the proficiency level of the students had a significant influence on the use of two categories of learning strategies: cognitive and compensation.

\section{Regression analysis}

The correlational analyses already revealed that imposter phenomenon and writing ability were not related. However, the prediction power of self-efficacy had to be calculated. Therefore, a linear regression analysis was run. Table 7 displays the model summary. Moreover, to explore the significance of the analysis, the ANOVA table was consulted (Table 8), which reveals a significant relationship.

\section{Table 7: Model Summary for self-efficacy and IP}

\begin{tabular}{lllll}
\hline Model & $\mathbf{R}$ & R Square & Adjusted R Square & Std. Error of the Estimate \\
$\mathbf{1}$ & $.314^{\mathrm{a}}$ & $\mathbf{. 0 9 9}$ & .079 & 8.01481 \\
\hline
\end{tabular}

a. Predictors: (Constant), IP, SE

As is clear in Table 7, the R Square or multiple correlation index is .099, indicating that about $10 \%$ of the variance in the students' writing ability scores is explained by the independent variable.

Table 8: ANOVA Table in regression analysis for self-efficacy and imposter

\begin{tabular}{lllllll} 
Model & & Sum of Squares & df & Mean Square & F & Sig. \\
\hline $\mathbf{1}$ & Regression & 639.332 & 2 & 319.666 & 4.976 & $.009^{\mathrm{a}}$ \\
& Residual & 5845.582 & 91 & 64.237 & & \\
& Total & 6484.915 & 93 & & & \\
\hline
\end{tabular}

a. Predictors: (Constant), IP, SE

b. Dependent Variable: Writing 
Table 9: Coefficient in regression analyses for self-efficacy and imposter phenomenon

\begin{tabular}{lllllll} 
& & \multicolumn{2}{l}{ Unstandardized Coefficients } & Standardized Coefficients & & \\
\cline { 3 - 6 } Model & & B & Std. Error & Beta & T & Sig. \\
\hline $\mathbf{1}$ & (Constant) & 20.551 & 6.812 & & 3.017 & .003 \\
& SE & .149 & .052 & $\mathbf{. 2 9 9}$ & 2.851 & $\mathbf{. 0 0 5 *}$ \\
& IP & .066 & .174 & .040 & .381 & .704 \\
\hline
\end{tabular}

a. Dependent Variable: Writing

Table 9 shows that regression is significant at the 0.01 level for the independent variable of self-efficacy, but not for the imposter phenomenon. That is, only self-efficacy significantly predicts writing ability. The Beta value of the predicting variable of self-efficacy reveals that one standard deviation unit change in the self-efficacy score would result in 0.29 units of change in writing ability.

\section{Conclusion}

For this group of learners, self-efficacy was positively and significantly related to learners' writing ability. Students who believed they could write and were confident in their skills performed better. Also, self-efficacy correlated positively with imposter phenomenon. It seems self-efficacious learners attributed their feeling of success to some external factors in $9 \%$ of the cases; in $91 \%$ of the cases they did not show imposter feelings. Learners' psychological traits such as their self-efficacy beliefs and imposter feelings should be taken into account by the FL educators in developing their writing ability. That is, to facilitate their performance in L2 writing, the instructors should enhance the learners' self-efficacy. A convenient atmosphere for students' learning is something that is suggested to be provided by teachers. In such an atmosphere, learners have the chance to promote their self-efficacy in the classroom and gain motivation and self-confidence while reducing anxiety and imposter feelings. In view of the prominence of writing, a vital issue for educational psychology is investigating the characteristics of effective instruction for writing. Since SE and IP are important factors in learning, students should become aware of their existence and their effects on their feeling and academic achievement. 


\section{References}

Allan, D. (2004). Oxford Placement Test. Oxford: Oxford University Press

Bandura, A. (1986). Social Foundations of Thought and Action: A Social Cognitive Theory. Englewood Cliffs, NJ: Prentice Hall.

Caselman, T.D., Self, P.A., \& Self, A.L. (2006). Adolescent Attributes Contributing to the Imposter Phenomenon. Journal of Adolescence, 29(3), 395-405.

Fried-Buchalter, Sh. (1992). Fear of success, fear of failure, and the imposter phenomenon: A factor analytic approach to convergent and discriminant validity. Journal of Personality Assessment, 58(2), 368-379.

Ghoreishi, S.M. (2003). EFL Learners' Oral communication Apprehension and its Relationship to their General Perceived Self-Efficacy. Unpublished MA thesis, Shiraz University, Shiraz, Iran.

Goh, C. M., \& Foong, K.P. (1997). Chinese ESL Students' Learning Strategies: A Look at Frequency, Proficiency, and Gender. Hong Kong Journal of Applied Linguistics, 2(1). Retrieved June 23, 2009 from www.sunzil.lib.hku.hk/hkjo/view/5/500018.pdf.

Klassen, R.M. (2007). Using Predictions to Learn about the Self-Efficacy of Early Adolescents with and without Learning Disabilities. Contemporary Educational Psychology, 32(2), 173-187.

Multon, K.D., Brown, S.D., and Lent, R.W. (1991). Relation of Self-Efficacy Beliefs to Academic Outcomes: A Meta-Analytic Investigation. Journal of Counseling Psychology, 38(1), 30-38.

Pajares, F. (1996). Self-Efficacy Beliefs in Academic Settings. Review of Educational Research, 66(4), 543-578.

Pajares, F. \& Graham, L. (1999). Self-Efficacy, Motivation Constructs, and Mathematics Performance of Entering Middle School Students. Contemporary Educational Psychology, 24, 124-139.

Pajares, F., Hartley, J. \& Valiante, G. (2000). Response Format in Writing Self-Efficacy Assessment: Greater Discrimination Increases Prediction. Paper presented at the meetings of the American Educational Research Association, New Orleans, April 2000. Retrieved November 25, 2008 from http://www.cc.emory.edu/EDUCATION/mfp/PHV2001MECD.PDF.

Pajares, F. \& Johnson, M. (1993). Confidence and Competence in Writing: The Role of Self Efficacy, Outcome Expectancy, and Apprehension. Paper presented at the annual meeting of The American Educational Research Association (Atlanta, GA, April 12-16).

Pajares, F., Johnson, M.J., \& Miller, M.D. (1999). Gender Differences in Writing Self-Beliefs of Elementary School Students. Journal of Educational Psychology, 91(1), 50-61.

Pajares, F. \& Miller, M.D. (1995). Mathematics Self-Efficacy and Mathematical Problem Solving: The Need for Specificity of Assessment. Journal of Counseling Psychology, 42 (2), 190-198.

Pajares, F. \& Schunk D.H. (2002). Self and Self Belief in Psychology and Education: An Historical Perspective. In Aronson, J. (Ed.) (2002). Improving Academic Achievement: Impact of psychological factors on education (pp. 3-21). San Diego, CA: Academic Press.

Pajares, F., \& Valiante, G. (1999). Grade level and gender differences in the writing selfbeliefs of middle school students. Contemporary Educational Psychology, 24, 390-405.

Pajares, F. \& Valiante, G. (2001). Gender Differences in Writing Motivation and Achievement of Middle School Students: A Function of Gender Orientation? ContemporaryEducational Psychology, 26, 366-381.

Pintrich, P., \& Schunk, D. (1996). The role of expectancy and self-efficacy beliefs. In P. Pintrich \& D. Schunk (Eds.), Motivation in education: theory, research, \& applications (Ch.3). Englewood Cliffs, NJ: Prentice-Hall. Retrieved 22 March, 2007 from: http://www.des.emory.edu/mfp/PS.html.

Thompson, T., Davis, H. \& Davidson, J. (1998). Attributional and Affective Responses of Impostors to Academic Success and Failure Outcomes. Personality and Individual Differences 25, 381-396.

Want, J. \& Kleitman, S. (2006). Imposter Phenomenon and Self-Handicapping: Links with Parenting Styles and Self-Confidence. Personality and Individual Difference, 40 (5), 961-971.

Weigle, C. S. (2002). Assessing Writing. Cambridge: Cambridge University Press.

Wick, S. (1997). The Impostor Phenomenon. Retrieved January 12, 2009 from http://www.ascb.org/index.cfm?navid=112\&id=1545\&tcode=nws3 